\title{
EDUCAÇÃO FÍSICA ESCOLAR E AS TRÊS DIMENSÕES DO CONTEÚDO: TEMATIZANDO OS ESPORTES NA ESCOLA PÚBLICA
}

\author{
Daniel Teixeira Maldonado, Universidade São Judas Tadeu, São Paulo - Brasil \\ Daniel Bocchini, Universidade Nove de Julho, São Paulo - Brasil
}

\begin{abstract}
RESUMO
Esse estudo descreve uma experiência pedagógica nas aulas de Educação Física onde os autores tematizaram os esportes. Realizado durante o $1^{\circ}$ semestre de 2013, para alunos do $7^{\circ}$ ano do Ensino Fundamental, de uma escola municipal localizada na zona leste do município de São Paulo, a pesquisa teve como enfoque as três dimensões do conteúdo. Na dimensão procedimental os alunos vivenciaram alguns esportes (futebol, vôlei, handebol, basquete, beisebol, atletismo e tênis) de acordo com as possibilidades de material, infraestrutura e habilidade motora no contexto escolar. Na dimensão conceitual foram realizadas aulas expositivas, análise de filmes e debates para que os alunos compreendessem o contexto histórico, as principais regras e os conceitos de saúde no esporte. Na dimensão atitudinal foram realizadas discussões envolvendo o preconceito racial no esporte. Após o desenvolvimento dessa experiência pedagógica, os alunos construíram uma visão diferenciada dos esportes realizados, compreenderam a história, as características desses esportes realizados no contexto escolar e a importância de respeitar todas as etnias que estão envolvidas nas praticas esportivas.
\end{abstract}

Palavras-Chave: Educação Física escolar; Esportes; Dimensões do conteúdo.

\section{SCHOOL PHYSICAL EDUCATION AND THREE DIMENSIONS OF CONTENTS: INSTRUCT SPORTS IN PUBLIC SCHOOL}

\begin{abstract}
This study describes a teaching experience in physical education classes where authors instruct sports. Performed during the 1st half of 2013, for students in 7th grade of elementary school, a public school located on the east side of São Paulo, the research was to approach the three dimensions of content. In procedural dimension students experienced some sports (football, volleyball, handball, basketball, baseball, athletics and tennis) according to the possibilities of material, infrastructure and motor skills in the school context. In conceptual dimension lectures, film analysis and debates were held for students to understand the historical context, the main rules and concepts of health in the sport. Attitudinal dimension in discussions involving racial prejudice in sport were held. After the development of this educational experience, students built a differentiated view of sports played, understand the history, the characteristics of these sports played in the school context and the importance of respecting all ethnic groups who are involved in sports practices.
\end{abstract}

Key-Words: School Physical Education; Sports; Dimensions of Content. 


\section{ESCUELA EDUCACIÓN FÍSICA Y TRES DIMENSIONES DE CONTENIDOS: ENSEÑANZA DEPORTES EN LA ESCUELA PÚBLICA}

\section{RESUMEN}

Este estudio describe una experiencia docente en las clases de educación física donde los autores enseñado deportes. Realizado durante la primera mitad de 2013, para los estudiantes de séptimo grado de la escuela primaria, una escuela pública ubicada en la zona este de São Paulo, la investigación era acercarse a las tres dimensiones del contenido. En los estudiantes de dimensiones procesales experimentado algunos deportes (fútbol, voleibol, balonmano, baloncesto, béisbol, atletismo y tenis) de acuerdo a las posibilidades de materiales, infraestructura y habilidades motoras en el contexto escolar. En conceptual se celebraron conferencias de dimensiones, el análisis de películas y debates para que los estudiantes comprendan el contexto histórico, las principales reglas y conceptos de salud en el deporte. Dimensión actitudinal en los debates relacionados con el prejuicio racial en el deporte se celebraron. Tras el desarrollo de esta experiencia educativa, los estudiantes construyen una visión diferenciada de los deportes que se practican, entienden la historia, las características de estos deportes que se practican en el contexto escolar y la importancia de respetar todos los grupos étnicos que están involucrados en las prácticas deportivas.

Palabras-Clave: Escuela de Educación Física; Deportes; Dimensiones de contenido. 


\section{INTRODUÇÃO}

A disciplina de Educação Física faz parte do currículo escolar há mais de 100 anos. Durante esse tempo, a prática pedagógica dos docentes desse componente curricular já foi influenciada pela instituição médica e militar, traduzindo em uma didática baseada nos currículos: ginástico e esportivista.

A partir da década de 1980, muitos pesquisadores começam a voltar para o Brasil após terminarem os cursos de doutorado no exterior e as ciências sociais e humanas começam a influenciar esses docentes durante a construção das teorias pedagógicas da Educação Física. Surge então uma análise crítica do paradigma da aptidão física, ocasionando muitas discussões e debates e o surgimento de diversas propostas elaboradas com a intenção de criar novas possibilidades didáticas para os professores que atuavam na escola. ${ }^{1}$

Em 2003, a professora Suraya Cristina Darido² lança um livro intitulado Educação Física na Escola: questões e reflexões. Nesse material a autora constrói um resumo de todas as propostas de Educação Física que surgiram após o inicio desses debates e elaboração de teorias pedagógicas para esse componente curricular. Todas essas ideias elaboradas tinham como principal intenção romper com o modelo esportivista e da melhora dos padrões físicos das pessoas. Os principais autores dessas propostas foram Betti, ${ }^{3}$ Brasil, ${ }^{4}$ Broto, ${ }^{5}$ Soares et al., ${ }^{6}$ Freire, ${ }^{7}$ Guedes, ${ }^{8}$ Guedes, ${ }^{9}$ Kunz,${ }^{10}$ Le Boulch, ${ }^{11}$ Tani et al. ${ }^{12}$

No final do século XX e inicio do século XXI começam a surgir propostas curriculares de Educação Física para a rede pública de ensino por todo o Brasil. Essas propostas nascem em consonância com os Parâmetros Curriculares Nacionais. Todos esses documentos propõem uma Educação Física que entenda o ser humano de forma integral, diversifica os conteúdos se baseando nas manifestações da cultura corporal de movimento, amplia as estratégias para ensinar e cria novos critérios de avaliação.

Isso indica que a Educação Física passa a estar integrada ao projeto político- pedagógico da escola e é pensada como as outras disciplinas dos diferentes níveis de ensino que compõe a Educação Básica. Portanto, os docentes dessa disciplina necessitam planejar as Conexões: revista da Faculdade de Educação Física da UNICAMP, Campinas, v. 12, n. 2, p. 147-165, abr./jun. 2014. ISSN: $1983-9030$ 
suas e ser coerente com esse planejamento durante a sua aplicação, tornando esses aprendizados significativos para as crianças e os adolescentes que frequentam essas aulas desde a Educação Infantil até o Ensino Médio. ${ }^{13}$

Sendo assim, o papel desse componente curricular ultrapassou o ensino dos temas da cultura corporal como apenas seus fundamentos e técnicas. O professor também necessita pensar nos conceitos que estão ligados aos procedimentos selecionados e nas reflexões que possam causar mudanças de atitudes dos alunos em relação aos conteúdos explorados nas aulas. $^{2}$

Influenciados por todas as discussões e debates realizados pelos docentes de Educação Física que discutem os currículos da escola, González e Fenstesrseifer ${ }^{15}$ acreditam que a Educação Física passou a ser considerada, nas últimas décadas, pelos acadêmicos e pela legislação, como um componente curricular. Dessa forma, essa disciplina escolar possui a finalidade de formar pessoas com consciência crítica para agir com autonomia em relação às manifestações da cultura corporal de movimento e munir o sujeito de possibilidades de se tornar um cidadão.

Mergulhados em todos esses debates sobre os currículos escolares, nos tornamos professores de Educação Física em escolas municipais de São Paulo. Para embasar a nossa prática pedagógica, planejamos ensinar os nossos conteúdos enfatizando as três dimensões do conteúdo. Nesse sentido, descreveremos nossa experiência de tematizar um dos conteúdos da cultura de corporal de movimento (Esportes), se preocupando em possibilitar vivências de diferentes esportes de interesse dos alunos, debater sobre a forma que essas práticas corporais devem ser realizadas na escola, refletir sobre o preconceito racial existente nessas modalidades esportivas e compreender os conceitos de saúde que a mídia explora durante a prática esportiva, que nem sempre está correto, com a intenção de tornar os nossos alunos do $7^{\circ}$ ano do Ensino Fundamental, sujeitos que possam atuar como cidadãos críticos e participativos na sociedade contemporânea.

\section{MÉTODO}


Realizamos um relato de experiência de uma prática pedagógica desenvolvida em uma escola municipal, localizada na zona leste da cidade de São Paulo, com alunos do $7^{\circ}$ ano do Ensino Fundamental, entre os meses de fevereiro e julho do ano de 2013. Embasamos-nos na etnografia para coletarmos os dados no cotidiano escolar. Utilizamos diários de campo, fotografamos as aulas e utilizamos todos os registros utilizados durante o processo de avaliação dos alunos para expressar nossas experiências nesse artigo.

Para Molina Neto, ${ }^{15}$ a etnografia é uma metodologia de pesquisa que vem sendo muito utilizada nos estudos realizados pelos pesquisadores que se preocupam com questões educacionais. Esse tipo de pesquisa qualitativa também vem sendo utilizado em projetos de inovação pedagógica, já que possibilita uma relação bastante interativa entre o sujeito e o objeto da investigação. É nessa linha que o sujeito que investiga alcança o papel de redescobridor da cultura que vivencia cotidianamente.

Portanto, a etnografia é uma importante metodologia para compreender questões relacionadas com a escola, podendo ser um instrumento satisfatório para que os professores possam produzir conhecimento a partir da prática cotidiana e refletir sobre a sua intervenção nos ambientes escolares, além de sistematizá-la e torná-la pública. ${ }^{15}$ Nesse sentido, decidimos mencionar a nossa experiência de tematizar os esportes para os nossos alunos enfatizando as três dimensões do conteúdo.

\section{RESULTADOS E DISCUSSÃO}

Ao iniciarmos o ano de 2013, tivemos a oportunidade de ministrar aula para o $7^{\circ}$ ano do Ensino Fundamental. Era o nosso primeiro contato com os alunos e sabíamos que os outros professores de Educação Física que tinham ministrado aula para essas turmas tinham uma didática completamente diferente daquela que acreditávamos, mas de uma forma ou de outra, muitos alunos gostavam de esportes.

Além disso, os professores de todas as disciplinas da escola decidiram em conjunto que o projeto político pedagógico desta unidade escolar iria estimular o protagonismo juvenil, o trabalho com as diferenças e reforçar a compreensão da leitura e da escrita dos alunos. 
Nesse sentido, a disciplina de Educação Física deveria selecionar conteúdos e estratégias que também atingissem esses objetivos.

Ao realizarmos o nosso planejamento traçamos os seguintes objetivos para as aulas: vivenciar algumas modalidades esportivas de acordo com o nível de habilidade dos alunos e as condições de infraestrutura da escola; compreender sobre a história e as principais regras dos esportes vivenciados; refletir sobre o que significa ser saudável no esporte; debater sobre o preconceito racial existente nos diferentes esportes praticados em várias partes do mundo e visitar locais que estimulem a reflexão sobre o esporte e a possibilidade de praticar diferentes modalidades esportivas.

A seguir, explicaremos as dinâmicas propostas para os alunos durante as aulas de Educação Física. Primeiramente, descreveremos as experiências que estiveram relacionadas com os conceitos desenvolvidos durante as aulas, logo após mostraremos as estratégias utilizadas para os alunos realizarem os esportes e para finalizar ressaltaremos quais foram as reflexões e os debates realizados sobre essa temática. Importante ressaltar que essa separação das experiências obtidas em aula foram sistematizadas apenas para melhor compreensão do leitor. No complexo do cotidiano escolar, esses aprendizados ocorreram ao mesmo tempo, de acordo com cada dinâmica que estava sendo realizada.

\section{DESENVOLVIMENTO DA PRÁTICA PEDAGÓGICA}

Para iniciar as aulas de esportes, realizamos algumas aulas expositivas, com a intenção de explicar sobre a história dessas modalidades e as suas principais regras. Discutimos com os alunos sobre futebol, vôlei, handebol, basquete, beisebol, atletismo e tênis. Importante ressaltar que os alunos tiveram a chance de visitar o museu do futebol para conhecer um pouco mais sobre esse esporte.

Após esse primeiro momento, fomos para a sala de informática e os alunos pesquisaram uma reportagem sobre um esporte que fosse do interesse de cada um deles. Após essa pesquisa, os trabalhos foram apresentados para o restante da turma. Surgiram diversos temas interessantes que foram discutidos durante as apresentações (utilização de anabolizantes pelos atletas, esportistas que terminaram as suas carreiras por lesões, 
discussões sobre o esporte durante a ditadura militar no Brasil, reportagens sobre preconceito racial e homofóbico no esporte e algumas reportagens mais convencionais sobre acontecimentos do dia a dia esportivo).

Ainda nesse momento, assistimos um documentário do canal Sportv que discutia sobre dor e lesão no esporte. Esse material trazia diversas entrevistas com atletas que ainda atuam no cenário nacional e internacional e alguns esportistas que já se aposentaram, discutindo principalmente como o esporte de alto nível causou dores, lesões e muitos machucados pelo corpo, mostrando que esse esporte competitivo não pode ser considerado saúde. Essa afirmação foi realizada várias vezes pelos médicos do esporte que também foram entrevistados durante o documentário.

Em contrapartida, discutimos sobre a recomendação de atividade física para a saúde com os discentes, mencionando que as crianças devem realizar ao menos 60 minutos de atividades físicas, por pelo menos cinco dias na semana e os adultos devem praticar ao menos 30 minutos de atividades físicas, por pelo menos cinco dias na semana, com intensidade moderada. Explicamos aos alunos que praticar esporte pelo tempo correto e com intensidade moderada faz muito bem para a saúde.

Depois de enfatizar os conteúdos conceituais planejados, decidimos praticar alguns desses esportes com os alunos. Porém, acreditamos que a escola não é palco de reproduzir as práticas esportivas exatamente como elas são realizadas fora dela, como já apontava o professor Francisco Eduardo Caparroz ${ }^{17}$ em 2007, no seu livro intitulado Entre a Educação Física na escola e a Educação Física da escola. Além disso, pautamos a nossa prática pedagógica na dimensão procedimental de acordo com a explicação de Kunz. ${ }^{10}$ Para o autor, o SE-MOVIMENTAR humano é caracterizado como a relação que o sujeito estabelece com a cultura a partir do seu repertório, informações/conhecimentos, movimentos e condutas, de sua história de vida, de suas vinculações socioculturais e de seus desejos. Nesse sentido, cada aluno realiza as diversas práticas corporais propostas nas aulas de Educação Física de acordo com as experiências que obteve na sua história de vida. 
Nesse sentido, criamos alguns jogos que se aproximavam dos esportes que queríamos tematizar nas aulas (fundamentos e regras parecidas), mas de uma forma que todos os alunos conseguissem participar das aulas de forma significativa.

O basquete foi jogado com uma atividade que chamamos de Basquete dos Cones (FIGURA 1). Nesse jogo, dividimos a quadra em quatro partes e em cada um desses locais um aluno segurava um cone e era considerado a cesta do jogo. Formamos dois times que ficavam na frente do cone e cada aluno tinha que arremessar a bola para tentar acertar a cesta. O time que realizasse dez pontos primeiro ganhava o jogo. Depois mantivemos a cesta (cone) nas extremidades de quadra e os alunos jogaram um jogo com as regras parecidas com a do basquete, mas tinham que fazer a cesta nesse cone. Importante ressaltar que os alunos que estavam segurando os cones podiam movimentar-se na tentativa de ajudar o seu time a realizar a cesta.

No atletismo realizamos diversas provas de corrida dessa modalidade esportiva (FIGURA 2). A corrida com obstáculos foi realizada com os alunos saltando sobre cones no espaço da quadra. Na prova de revezamento os discentes tinham que correr até um espaço da quadra e passar uma caneta para o colega do seu time. Esse aluno corria e passava a caneta para o próximo até chegar ao último da fileira. A equipe em que todos os alunos realizassem esse procedimento primeiro era vencedora. Também realizamos uma atividade que se aproximava da marcha atlética, onde os alunos realizavam movimentos aproximados com essa prova, indo e voltando de um lado até o outro da quadra, a corrida de 100 metros, onde os alunos corriam da forma mais rápida possível até o final da quadra e voltavam e, para finalizar, simulamos uma maratona, onde os alunos correram de forma moderada por 10 minutos e depois discutimos quais eram as sensações corporais que eles sentiam (batimentos do coração, quantidade de sangue no corpo para gerar energia, cansaço e sudorese).

O Beisebol foi ensinado com um jogo conhecido entre os professores de Educação Física chamado Base 4 (FIGURA 3). Nessa atividade, dividimos a sala em dois times (ataque e defesa). O time do ataque forma uma fila e um aluno por vez rebatia uma bola de vôlei e tentava passar por quatro bases (cones) colocadas no time da defesa sem ser queimado. $\mathrm{O}$ 
time de defesa se espalhava pelo espaço e tinham que impedir que os atacantes conseguissem passar pelas bases queimando esses alunos. Depois o time do ataque ia defender e os defensores iam atacar. A equipe que mais alunos passassem pelas quatros bases sem ser queimado ganhava o jogo.

O futebol foi realizado com um jogo que chamamos de Futebol Família (FIGURA 4). Os alunos se dividiam em suas equipes e formavam um círculo em cada lado da quadra. Cada um dos times tinha que ficar de mãos dadas no círculo, tocar a bola até chegar no gol adversário, permitir que todos os alunos realizassem um toque na bola e o último chutava para o gol. A equipe que conseguisse realizar o gol realizando todos esses procedimentos ganhava o jogo. Importante ressaltar que durante o percurso das equipes, caso a bola saísse do círculo, os participantes tinham que voltar para o local que iniciaram o jogo e começar tudo de novo.

Realizamos o vôlei com um jogo chamado Rede Humana (FIGURA 5). Dividimos os alunos em três times, sendo que um deles era rede e os outros dois jogavam vôlei com regras muito parecidas dessa modalidade esportiva jogada no alto nível. A única diferença é que os alunos não realizavam todos os fundamentos do esporte, podendo segurar e passar a bola com as duas mãos (câmbio). Outra diferença era que todas as vezes que uma das equipes realizasse um ponto, a equipe que sofreu a pontuação virava rede e a equipe que estava na rede ia jogar.

O handebol foi realizado com um jogo chamado Bola ao Capitão. Os alunos foram divididos em dois times e jogaram com as regras muito parecidas com as do esporte convencional. A principal diferença foi que o gol era realizado quando o capitão de cada uma das equipes, que ficava posicionado na área do goleiro adversário, conseguisse segurar a bola advinda de um arremesso dos participantes do seu time.

No jogo de tênis, os alunos foram divididos em cinco grupos e espalhados pela quadra toda. Cada grupo recebeu duas raquetes de tênis (material emprestado de outra escola). Os alunos foram formando duplas e rebatendo a bolinho por cima de uma corda que ficava presa em dois cones. Quando um dos jogadores fazia três pontos, os dois alunos que 
estavam jogando saiam e outros dois entravam para jogar. O ponto era realizado toda a vez que a bolinha pingasse duas vezes no espaço de quadra do adversário.

Todas as adaptações realizadas nos esportes tiveram como principal objetivo facilitar a participação de todos os alunos na aula. Acreditamos que obtivemos sucesso nessas adaptações, pois em todas as aulas os alunos participaram de forma efetiva e ninguém se negou a realizar os esportes propostos. Em alguns momentos, também permitíamos que os próprios discentes realizassem palpites no formato dos jogos praticados e modificassem algumas regras, com a intenção que o jogo ficasse mais dinâmico para o nível de habilidade de cada uma das turmas. Abaixo, mostraremos algumas fotos dos jogos realizados em aula.

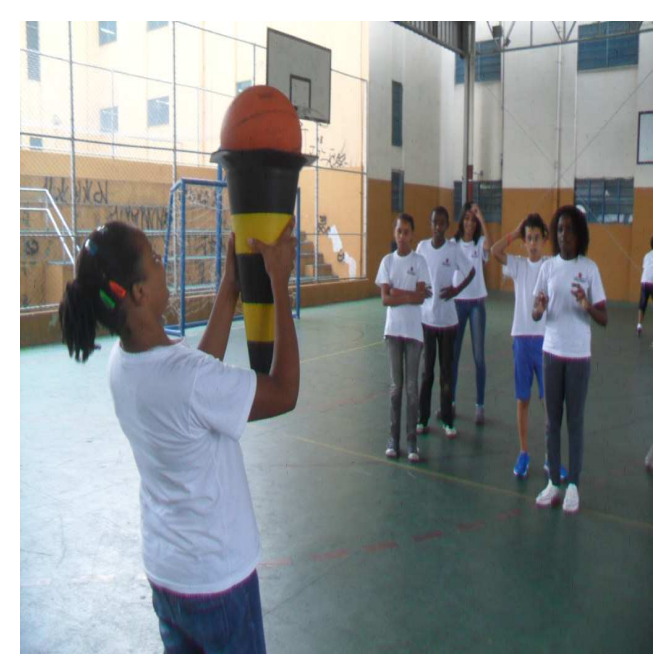

Figura 1: Basquete.

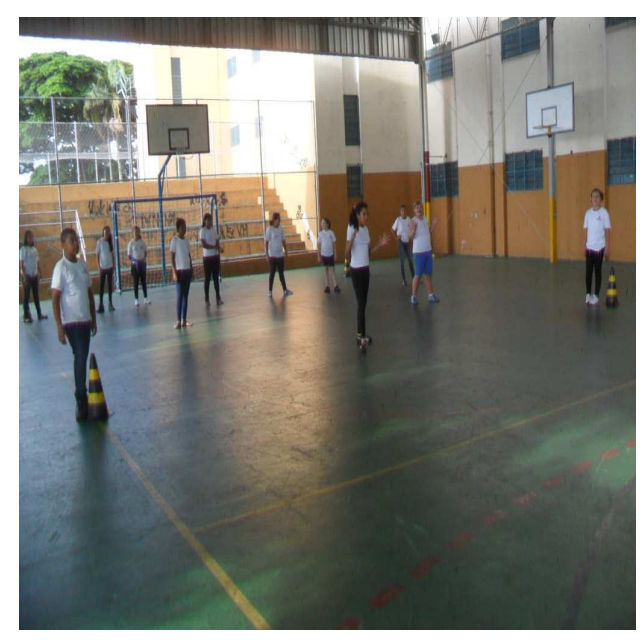

Figura 3: Beisebol.

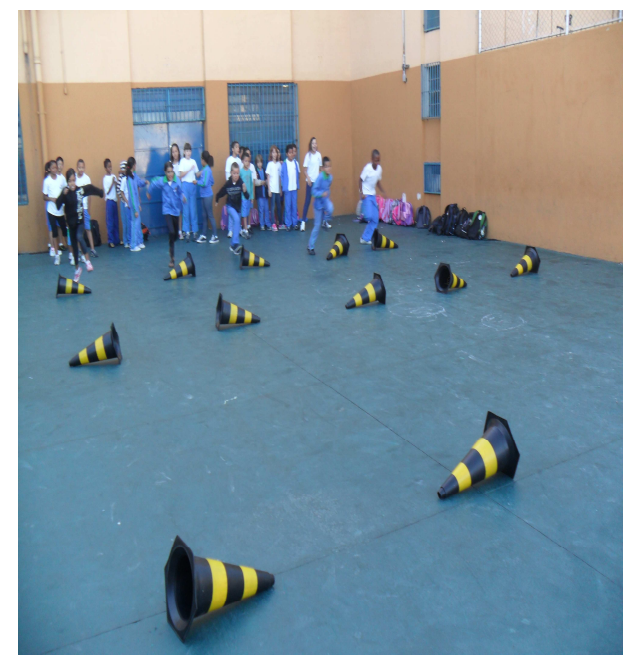

Figura 2: Atletismo.

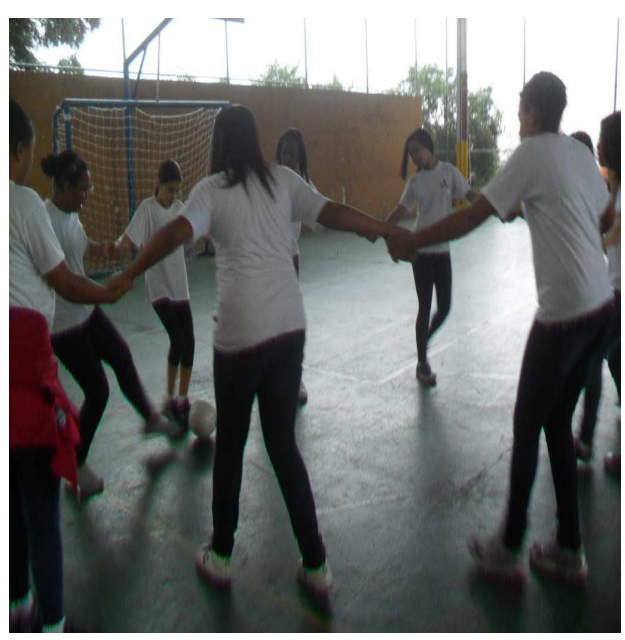

Figura 4: Futebol.

Conexões: revista da Faculdade de Educação Física da UNICAMP, Campinas, v. 12, n. 2, p. 147-165, abr./jun. 2014. 


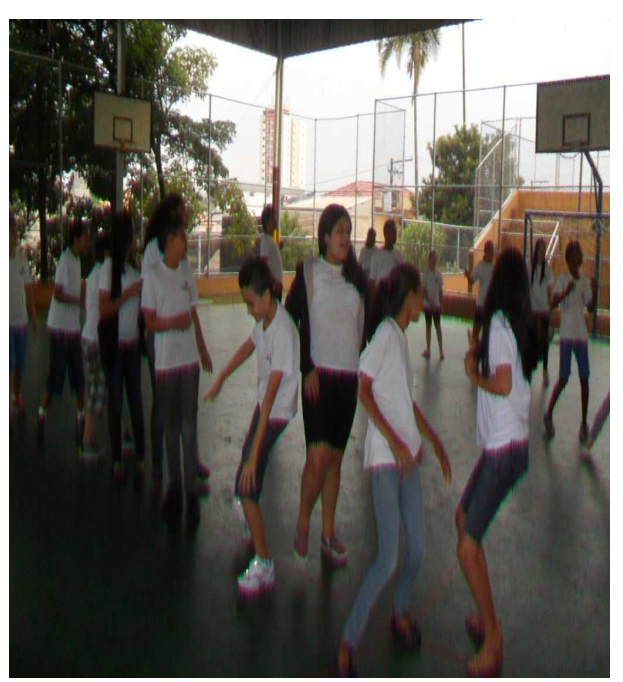

Figura 5: Vôlei.

Depois dos alunos realizarem essas aulas, tínhamos a intenção de diagnosticar como que os discentes compreenderam os esportes que eles jogaram. Então, voltamos para a sala de aula e pedimos que eles escrevessem os esportes que foram realizados e também fizessem um desenho explicativo sobre essa atividade. A seguir, mostraremos como dois alunos realizaram essas tarefas propostas em aula (FIGURAS 6; 7) .

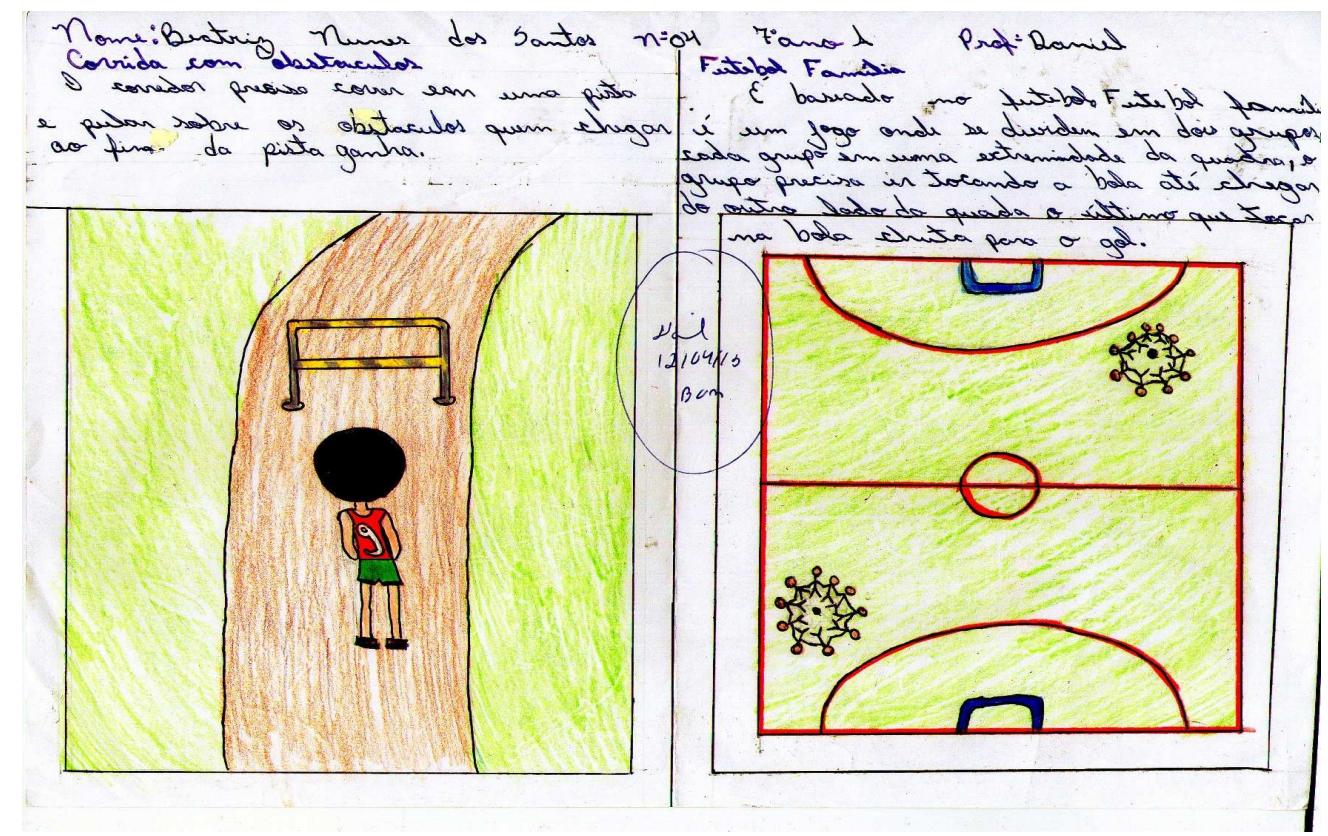

Figura 6: Compreensão da atividade realizada pelo Aluno 1. 


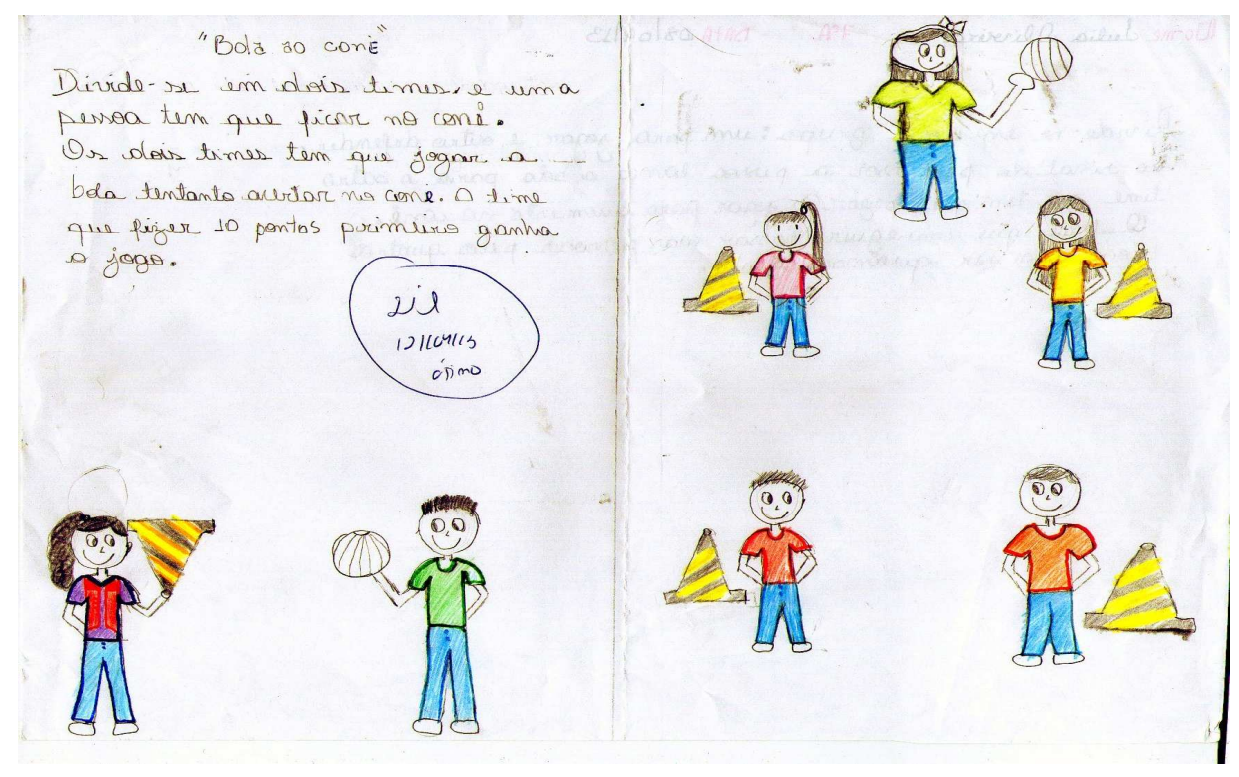

Figura 7: Compreensão da atividade realizada pelo Aluno 2.

Logo após os alunos explicarem os jogos que ensinamos, realizamos uma proposta um pouco diferente. Pedimos que os discentes criassem um jogo parecido com um esporte, onde todos os alunos conseguissem jogar de forma satisfatória e com segurança. Uma aluna criou um esporte chamado Basquete em Família, onde cada equipe ficava de mão dada perto de uma das cestas e o primeiro aluno tinha que conseguir fazer os pontos. Quando a cesta fosse realizada, esse aluno ia para o final da fila e o próximo tentava realizar os pontos. A equipe que todos os alunos conseguissem realizar a cesta vencia o jogo. Abaixo, segue o desenho explicativo desse esporte elaborado pela aluna (FIGURA $8)$.

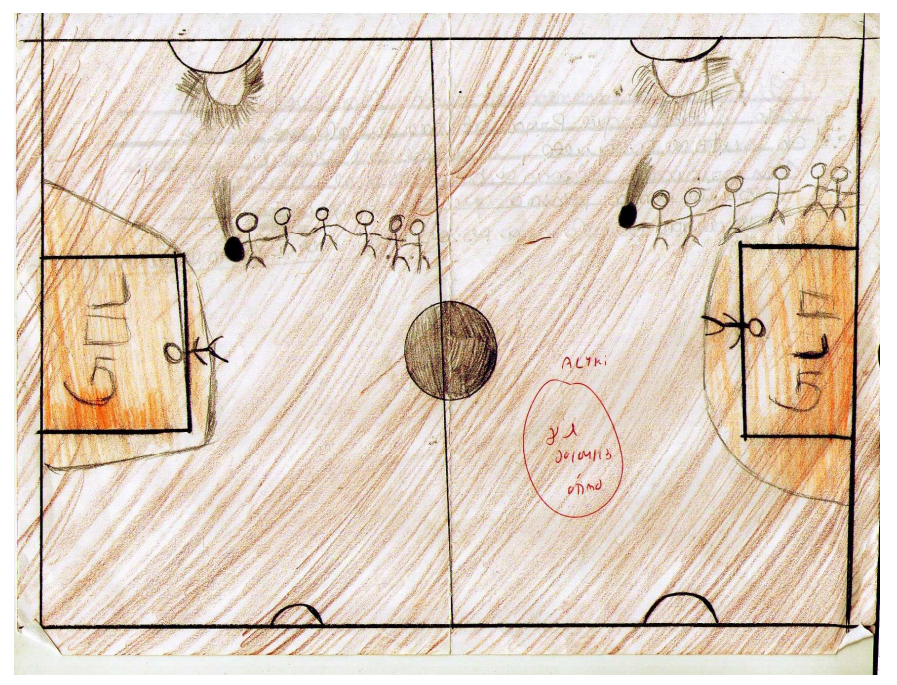

Figura 8: Compreensão da atividade realizada pelo Aluno 3.

Conexões: revista da Faculdade de Educação Física da UNICAMP, Campinas, v. 12, n. 2, p. 147-165, abr./jun. 2014. ISSN: $1983-9030$ 
Outra aluna também criou um jogo muito interessante nomeado por ela de Queimada Beisebol. Nesse jogo, os alunos foram separados em dois times para realizar um jogo de queimada convencional. A aluna também propôs que fossem colocados quatro cones nas pontas da quadra, como foi realizado no Beisebol, e que todas as vezes que uma das equipes conseguisse queimar um colega do time adversário, o aluno que queimou tinha que passar correndo pelos quatro cones sem ser queimado pelos integrantes do time adversário. Se ele conseguisse esse feito, a sua equipe ganhava dois pontos, um por ter queimado uma das pessoas do time adversário e outro por ter conseguido passar pelos quatro cones. Cada um dos times ainda tinha um rei ou rainha e se essa pessoa fosse queimada pelo time adversário, automaticamente o jogo acabava. Somente o professor sabia que era nomeado como rei e rainha pelas suas equipes. Segue abaixo o desenho explicativo da aluna.

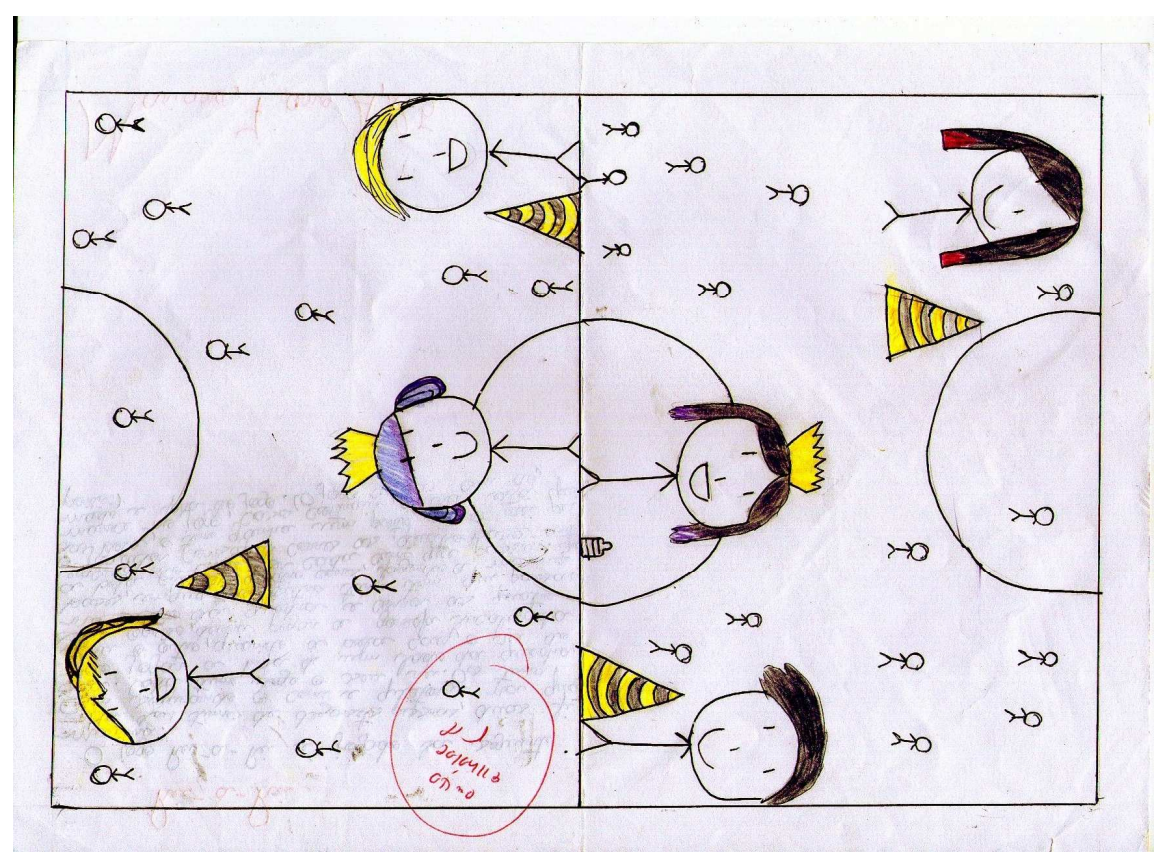

Figura 9: Compreensão da atividade realizada pelo Aluno 4.

Outros alunos também criaram jogos interessantes e escolhemos dois desses jogos em cada uma das salas para que todos praticassem as atividades propostas pelos próprios alunos. Nossa principal intenção nesse momento da aula era estimular a criatividade dos discentes e mostrar que eles também poderiam criar jogos ou esportes interessantes, assim como Willian Morgan criou o vôlei ou o James Naismith criou o basquete há mais de 100 anos atrás. 
Durante o andamento das aulas, percebemos que muitos alunos tinham brincadeiras preconceituosas com seus colegas, principalmente devido as diferentes etnias dos discentes. Além disso, a mídia mostrava muitas vezes atitudes racistas de vários torcedores ao redor do mundo, principalmente no futebol. Decidimos então assistir ao filme Estrada para a Glória, pois essa obra cinematográfica mostra como que a primeira equipe norteamericana universitária formada apenas por negros conseguiu vencer um campeonato de extrema importância. Os alunos assistiram tudo que esses jovens afrodescendentes sofreram para ganhar respeito das pessoas de pele clara, pois elas tinham muito preconceito racial naquele momento. Após assistir ao filme, realizamos um debate em sala de aula sobre o assunto e os alunos escreveram um texto sobre o filme e entregaram esse material para computar como uma das avaliações realizadas no bimestre.

Utilizamos todos os trabalhos dos alunos para realizar a avaliação do processo de ensino e aprendizagem, além de nossa prova formal, que é realizada todo o final de bimestre. $\mathrm{O}$ conceito emitido para os alunos durante as nossas aulas de Educação Física foram produzidos a partir da participação dos esportes realizados, das notas recebidas pelos trabalhos, pela participação nas discussões em aula e pela nota recebida na prova.

Para finalizar a tematização desse tema durante as aulas, realizamos um passeio com os alunos para o SESC Itaquera na intenção que eles pudessem praticar diversas modalidades esportivas durante um dia inteiro. Abaixo, segue uma foto com alguns alunos dessas turmas que participaram desse passeio (FIGURA 10).

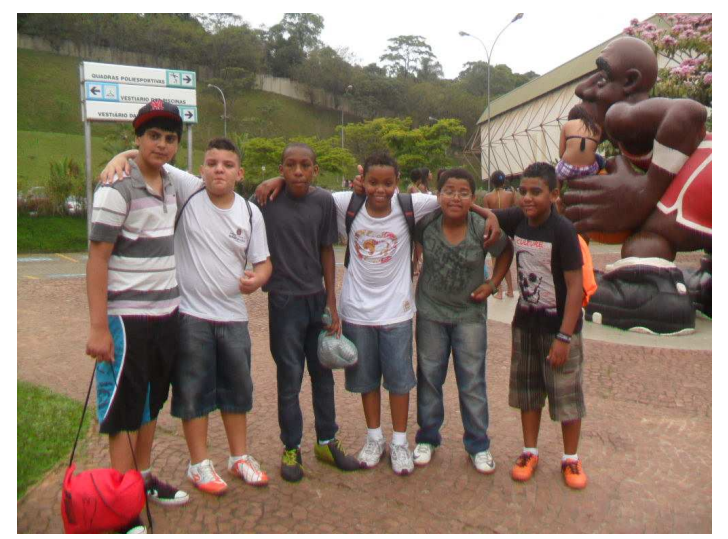

Figura 10: Passeio para o SESC Itaquera.

Conexões: revista da Faculdade de Educação Física da UNICAMP, Campinas, v. 12, n. 2, p. 147-165, abr./jun. 2014.

ISSN: 1983-9030 
Diversos pesquisadores que se preocupam em mostrar práticas pedagógicas inovadoras, pautadas nas três dimensões do conteúdo, também publicaram os seus estudos em periódicos científicos, com a intenção de compartilhar essas experiências pedagógicas que estão sendo realizadas no "chão das escolas". Esses relatos de experiências relataram experiências pedagógicas com atletismo, voleibol, ginásticas, lutas, danças e futebol. ${ }^{18-24}$

Como podemos perceber, são muitos os autores que publicaram experiências pedagógicas inovadoras realizadas na escola. Em todos esses estudos, os professores de Educação Física se preocuparam em ensinar os seus conteúdos enfatizando os procedimentos, os conceitos e as atitudes existentes naquela prática corporal, proporcionando aos seus alunos uma variedade de aprendizagens, com a intenção de torná-los cidadãos com maior consciência crítica para atuar na sociedade.

\section{DIFICULDADES PARA REALIZAR A EXPERIENCIA PEDAGÓGICA}

Durante as aulas de esportes nessa escola, nossa maior dificuldade foi a resistência dos alunos com o conteúdo. Os outros docentes de Educação Física dessa unidade escolar realizavam um trabalho mais voltado para as competições esportivas e tinham objetivos muito diferentes dos nossos. Nesse sentido, tivemos muitos obstáculos para os discentes entenderem a nossa proposta. No inicio, muitos alunos tinha resistência de participar da aula ou participavam de qualquer jeito, mas com o tempo as coisas foram melhorando um pouco e as aulas ocorreram de forma mais satisfatória.

As aulas teóricas foram a nossa maior dificuldade, pois os alunos tinham uma ideia que a Educação Física na escola servia muito mais como um momento de lazer ou de competição do que um momento de reflexão e aprendizagem. Realizar análises de filmes e fazer trabalhos na sala de informática foram estratégias eficientes, principalmente porque os alunos se envolviam com essas atividades muito mais do que quando precisavam escrever da lousa e ler algum material impresso em sala de aula.

Tivemos alguns problemas de indisciplina em algumas turmas. Parece-nos que quando se inicia um trabalho novo em uma escola, os alunos testam o professor para saber quais são 
os seus limites e não foi diferente conosco. A principal dificuldade nesse momento foi quando nas atividades propostas os alunos tinham que ficar em vários grupos dispersos na quadra. No inicio das aulas, por muitas vezes, percebemos que alguns discentes não jogavam direito ou faziam brincadeiras durante a aula. Nossas intervenções foram sendo realizadas nesses momentos e com o passar do tempo essa resistência foi diminuindo.

Realizar discussões específicas sobre o preconceito racial na escola também foi um momento delicado, já que era um dos primeiros contatos com a turma e os alunos podiam interpretar de forma errônea o que queríamos dizer. A nossa postura sempre foi muito séria nesses momentos, sem nenhum tipo de brincadeira, para tentar com a nossa postura modificar minimamente o comportamento malicioso de alguns alunos em relação às atitudes preconceituosas que existia entre eles.

\section{REFLEXÕES FINAIS}

Ao terminar essa experiência pedagógica e as vivências de esporte com essas turmas, acreditamos que os alunos compreenderam um pouco mais sobre a história e as regras das modalidades discutidas em aula, refletiram sobre o discurso de saúde no esporte de alto nível e do preconceito racial existente no seio da sociedade e é refletido dentro da prática esportiva e perceberam que possuem condições de criar jogos interessantes, assim como também podem fazer outras coisas boas em suas vidas.

Houve muitos obstáculos durante a tematização desse conteúdo na escola. A resistência dos alunos frente ao formato que foi tratado esse conteúdo, os preconceitos dos próprios adolescentes com as diferentes etnias existentes na escola e a indisciplina e alguns discentes dificultaram bastante o processo, mas foram superados na medida do possível.

Terminamos as aulas de esporte com a certeza de que os objetivos traçados no inicio do planejamento foram alcançados, principalmente porque as avaliações realizadas durante o processo demonstravam que os discentes tinham compreendido o conteúdo e os debates de ordem social que foram realizados durante as aulas.

Conexões: revista da Faculdade de Educação Física da UNICAMP, Campinas, v. 12, n. 2, p. 147-165, abr./jun. 2014. ISSN: 1983-9030 


\section{REFERÊNCIAS}

${ }^{1}$ BRACTH, V. A constituição das teorias pedagógicas da Educação Física. Cadernos Cedes, Campinas, ano 19, n. 48, ago. 1999.

${ }^{2}$ DARIDO, S. C. Educação física na escola: questões e reflexões. Rio de Janeiro: Guanabara Koogan, 2003.

${ }^{3}$ BETTI, M. Educação física e sociedade: a Educação Física na escola brasileira de $1^{\circ}$. e $2^{\circ}$ graus. São Paulo: Movimento, 1991.

${ }^{4}$ BRASIL. Ministério da Educação. Secretaria de Educação Fundamental. Parâmetros Curriculares Nacionais: educação física. Brasília, 1998.

${ }^{5}$ BROTO, F. O. Jogos cooperativos: se o importante é competir, o fundamental é cooperar. São Paulo: Cepeusp, 1995.

${ }^{6}$ SOARES, C. L. et al. Metodologia do ensino de educação física. São Paulo: Cortez, 1993.

${ }^{7}$ FREIRE, J. B. Educação de corpo inteiro: teoria e prática da Educação Física. Campinas: Scipione, 1989.

${ }^{8}$ GUEDES, D. P. Educação para saúde mediante programas de Educação Física Escolar. Motriz, Rio Claro, v. 5, n. 1, junho, 1999.

${ }^{9}$ GUEDES, D. P. Educação Física Escolar com ênfase em educação para a saúde. CONGRESSO INTERNACIONAL DE EPISTEMOLOGIA DA EDUCAÇÃO FÍSICA, 1. 2006, São Paulo. Anais... São Paulo, 2006.

${ }^{10}$ KUNZ, E. Transformação diático-pedagógica do esporte. 4. ed. Ijuí: Ed. da Unijuí, 2001.

Conexões: revista da Faculdade de Educação Física da UNICAMP, Campinas, v. 12, n. 2, p. 147-165, abr./jun. 2014. 
${ }^{11}$ LE BOULCH, J. A educação pelo movimento: a psicocinética na idade escolar. Porto Alegre: Artes Médicas, 1983.

${ }^{12}$ TANI, G. et al. Educação física escolar: fundamentos de uma abordagem desenvolvimentista. São Paulo: EPU, 1988.

${ }^{13}$ CAMPOS, M. C. As finalidades educacionais na Educação Física e a prática reflexiva: concepções e possibilidades na educação básica. In: SCARPATO, M. Educação física: como planejar as aulas de Educação Física. São Paulo: Avercamp, 2007.

${ }^{14}$ DARIDO, S. C. et al. A Educação Física, a formação do cidadão e os Parâmetros Curriculares Nacionais. Revista Paulista de Educação Física, São Paulo, v. 15, n. 1, p. 17-32, jan./jun. 2001.

${ }^{15}$ GONZÁLEZ, F. J.; FENSTERSEIFER, P. E. Entre o "não mais" e o "ainda não": pensando saídas para o não lugar da EF escolar II. Cadernos de Formação RBCE, p. 1021, mar. 2010.

${ }^{16}$ MOLINA NETO, V.; TRIVIÑOS, A. N. S. A pesquisa qualitativa na Educação Física: alternativas metodológicas. In: Etonografia: opção metodológica para alguns problemas de investigação no âmbito da Educação Física. 3. ed. Porto Alegre: Sulina, 2010.

${ }^{17}$ CAPARROZ, F. E. Entre a educação física na escola e a educação eísica da escola. 3. ed. São Paulo: Autores Associados, 2007.

${ }^{18}$ BARROSO, A. L. R.; DARIDO, S. C. Voleibol escolar: uma proposta de ensino na dimensão conceitual, procedimental e atitudinal do conteúdo. Revista Brasileira de Educação Física e Esporte, v. 24, n. 2, p. 179-194, abr./jun. 2010. 
${ }^{19}$ MALDONADO, D. T.; BOCCHINI, D. Prática pedagógica diferenciada nas aulas de Educação Física: a ginástica na escola pública. Coleção Pesquisa em Educação Física, v. 12, n. 1, p. 165-172, 2013a.

${ }^{20}$ MALDONADO, D. T.; BOCCHINI, D. As três dimensões do conteúdo na educação física: tematizando as lutas na escola pública. Conexões: revista da Faculdade de Educação Física da UNICAMP, Campinas, v. 11, n. 4, p. 195-211, 2013 b.

${ }^{21}$ MALDONADO, D. T.; BOCCHINI, D. As três dimensões do conteúdo na educação física: tematizando as danças na escola pública. Conexões: revista da Faculdade de Educação Física da UNICAMP, Campinas, v. 12, n. 1, p. 181-200, 2014.

${ }^{22}$ MASCARA, D. I.; CHIMINAZZO, J. G. C.; LIMA, N. M. O futebol da escola: construção de uma proposta baseada nas três dimensões dos conteúdos Pulsar, v. 5, n. 1, 2013.

${ }^{23}$ MATTHIESEN, S. Q.; SILVA, M. F. G.; SILVA, A. C. L. Motriz, Rio Claro, v. 14, n. 1, p. 96-104, 2008.

${ }^{24}$ RODRIGUES, H. A; DARIDO, S. C. As três dimensões do conteúdo na prática pedagógica de uma professora de Educação Física com mestrado: um estudo de caso. Revista da Educação Física/UEM, Maringá, v. 19, n. 1, p. 51-64, 2008. 